Revérbero Constitucional

Fluminense, Press and

Constitutionalism at Court in

the Independence

\title{
0 Revérbero Constitucional Fluminense, Imprensa e Constitucionalismo na Corte na Independência
}

\author{
Virgínia Rodrigues da Silva \\ Mestranda em História pela \\ Universidade Federal Fluminense \\ (RJ/Brasil) \\ e-mail: virginia_rsilva@yahoo.com.br
}

\begin{abstract}
Resumo
Esta pesquisa pretende lançar luz sobre as especificidades das propostas políticas e projetos de Estado e nação no processo de Independência, que recorrentemente variavam de acordo com o momento, o espaço geográfico e o lugar social a partir do qual eram veiculadas. Partiremos da análise de um dos principais jornais da polemista imprensa de opinião da Corte no periodo de 1821-1822, o Revérbero Constitucional Fluminense, publicado por Joaquim Gonçalves Ledo e Januário da Cunha Barbosa. Objetivamos o entendimento das fronteiras e pertencimentos que caracterizavam sua identidade política, definida em meio às transformações (não evolutivas) do espaço público e da afirmação, por formas enviesadas e diversas, de uma cultura política baseada nos princípios do constitucionalismo liberal. Com isso, pretendemos estabelecer de que forma a noção de soberania e as variadas vertentes do pensamento constitucionalista e liberal de fins do século XVIII e início do século XIX manifestaram-se no discurso do jornal.
\end{abstract}

\begin{abstract}
The research aims at shedding light over the specifics of political propositions and state and nation projects in the process of Independence, all of which recurrently varied according to moment, geographic space and the social place from which they were circulated. Our starting point shall be the analysis of one of the main newspapers from the Court's opinion press in the period ranging from 1821 to 1822, the Revérbero Constitucional Fluminense, published by Joaquim Gonçalves Ledo and Januário da Cunha Barbosa. Our objective is to understand the frontiers and belongings that characterized its political identity, defined amidst public space transformation and the affirmation, by means of biased and diverse manners, of a political culture based on the principles of liberal constitutionalism. By doing so, we intend to establish the ways in which the notion of sovereignty and the many varieties of constitutionalist and liberal thought at the end of the 18th century and the beginning of the 19th century took place in the newspaper's discourse.
\end{abstract}

\section{Palavras-chave}

Independência, imprensa, monarquia, representações políticas

\section{Keywords}

Independence, press, monarchy, political representations 
D. João VI assinou decreto em 2 de março de 1821 suspendendo a censura prévia.

Sobre o amplo e diverso sistema de adesões em torno do príncipe, ver: SOUZA, lara Lis Carvalho. A Pátria Coroada: o Brasil como corpo político autônomo (1780 - 1831). São Paulo: Editora da UNESP, 1999.

Sobre estes processos no contexto brasileiro, ver: MOREL, Marco. As transformações dos espaços públicos: imprensa, atores políticos e sociabilidades na Cidade Imperial, 1820-1840. São Paulo: Hucitec, 2005.

Januário da Cunha Barbosa foi pregador da Capela Real, e Joaquim Gonçalves Ledo foi nomeado secretário e procurador da Província do Rio de Janeiro, atuando no Conselho de Estado de junho de 1822 a 15 de outubro de 1822. Ademais ambos eram ligados ao presidente da Câmara do Rio de Janeiro, José Clemente Pereira.

5

Para uma demarcação do perfil coletivo dos agentes que publicaram impressos (panfletos e/ou jornais periódicos) e também participavam de associações públicas no Rio de Janeiro entre 1820 e 1840, ver: MOREL, Marco. Op.Cit., p.167-199.

6

A expressão "Cidade-Corte" é de Marco Morel, que analisa o Rio de Janeiro como lugar privilegiado do debate político público. MOREL, Marco. Op.Cit., p.151-166.

7

Renato Lopes Leite identificou no Correio e no Revérbero uma suposta imprensa republicana radical, que se valeria da estratégia de criticar furiosamente monarquia absolutista e defender o governo constitucional representativo estabelecido por meio de uma Assembléia Constituinte. Em seu texto, como referenciais de análise, 0 autor adotou principalmente trechos dos jornais e os depoimentos e acusações de antagonistas contidos no "Processo", instaurado por Bonifácio a 2 de novembro de 1822, contra àqueles redatores, entre outros. LEITE, Renato Lopes. Republicanos e libertários: pensadores no Rio de Janeiro (1822). Rio de Janeiro: Civilização Brasileira, 2000.
Os anos entre 1820 e 1822 foram importantes para o florescimento da imprensa de opinião em decorrência das medidas que estabeleceram sua liberdade de circulação no Brasil' ${ }^{1}$, mas também por conta do largo uso dos jornais como instrumento político-doutrinário. Nos novos temas levantados pelo triunfo do movimento constitucionalista em 1820, e nas questões políticas referentes às relações entre os Reinos, estavam alguns dos assuntos que contribuiram para o incremento da imprensa regular. Estreitamente vinculados à atividade política exercida pelos mais variados agentes sociais e facções, os quais representavam direta ou indiretamente, os jornais de opinião expressaram, em estilo retórico, o embate políticoideológico que, a despeito da articulação comum que apoiou a emancipação política ${ }^{2}$, marcou com características controversas o processo de Independência.

A partir da análise do Revérbero Constitucional Fluminense, pretende-se contribuir para a investigação da trajetória, das concepções politicas e culturais de agentes com destacado papel político no processo de Independência: Joaquim Gonçalves Ledo e Januário Cunha Barbosa, donos do jornal e integrantes das elites do Brasil Imperial. Estes integrariam a primeira geração de jornalistas ou panfletários, também chamados de redatores ou gazeteiros, cuja figura se firmava em sintonia com a afirmação da esfera pública e da politização das opiniões ${ }^{3}$. Delinear a participação intelectual dos redatores do Revérbero, entretanto, não significa esquecer suas circulações no poder instituído ou ignorar suas relações diretas com ele 4 . Busca-se apenas analisar a atuação desses agentes situados nos grupos das elites tendo em conta o contexto em que estavam inseridos, marcado pelas disputas políticas no âmbito da imprensa. Além disso, estes homens de letras, assim como o oficial-maior da contadoria do arsenal do exército Ledo e o cônego e lente de filosofia racional e moral Cunha Barbosa até agora se mostraram, pertenciam, muitas vezes, a setores intermediários da hierarquia social, atuando como professores, padres, funcionários públicos e advogados. Muitos não possuiam pertencimento direto a linhagens de elementos administradores do Estado português ou de grandes proprietários rurais 5 . Isto é, incluiam-se entre os personagens urbanos, cuja atuação política tornou-se possível no contexto de transformações políticas, econômicas e culturais que erigiram o Rio de Janeiro à condição de "Cidade-Corte", com vida e tensões urbanas e importância política de Corté .

\section{0 Revérbero e a política na Independência: algumas questões historiográficas}

A posição do Revérbero e de seus redatores no processo de Independência, assim como a própria questão das tendências e identidades políticas no Brasil na primeira metade do século XIX, é um tema reconhecidamente complexo. Como outros periódicos que circularam naqueles anos, 0 jornal teve o conteúdo dos escritos e as circunstâncias específicas de sua produção, por vezes, relegados a um segundo plano, em detrimento das qualificações elaboradas por adversários políticos dos seus redatores e de João Soares Lisboa, redator do Correio do Rio de Janeiro, todos atuantes de destaque na defesa pela instituição da Assembléia Constituinte, convocada por D. Pedro com o propósito de formar a futura Constituição do Brasil7. Como se sabe, a convocação das Cortes na América em 3 de junho de 1822, em reunião do Conselho de Procuradores das Províncias, por sua vez 
Para a repercussão dessa discussão no Rio de Janeiro e nas Cortes em Lisboa. BERBEL, Márcia. A Nação como artefato: deputados do Brasil nas Cortes portuguesas. 1821-1822. São Paulo: Hucitec, 1999.

9

Sobre a questão da memória na historiografia da Independência ver: OLIVEIRA, Cecília Helena Lorenzini de Salles. A astúcia liberal. Bragança Paulista: Edusf e İ́cone, 1999.

\section{0}

Para Nelson Werneck Sodré, na sua História da Imprensa no Brasil o Revérbero seria o "órgão doutrinário da independência brasileira", sobretudo por sua defesa da instituição de uma Assembléia Constituinte, o que teria significado, já em meados de 1822, "embora não se declarasse explicitamente" que "a independência estava consumada". SODRÉ, Nelson Werneck. A História da Imprensa no Brasil. Rio de Janeiro: Civilização Brasileira, 1966. p.62-64.

\section{1}

A título de exemplificar esta interpretação, aludimos a divisão ideológica entre "direita" e "esquerda" que fez Werneck Sodré ao analisar as disputas do período com significações políticas análogas às dos anos de 1960, que data a sua obra. SODRÉ, Nelson Werneck. Op.Cit.

\section{2}

0 influente trabalho Introdução ao estudo da emancipação politica do Brasil de Emilia Viotti da Costa, apontou a presença, na Corte em 1822, de um partido republicano composto por círculos de tendências mais radicais e democratas, predominantemente ligados a atividades urbanas. Uma importante vertente deste grupo seria liderada pelos redatores do Revérbero, que assim como outros de seu "partido", diante da oportunidade de fazer a Independência sob o comando do Principe, terminaram por aderir à solução monárquica, sem a mobilização popular. Na visão da autora, o conflito envolvendo os grupos políticos na Corte separou estes "radicais", de vocação republicana, das forças sociais "conservadoras", defensoras da monarquia e dos privilégios das classes agrárias, representadas na figura de Bonifácio e José da Silva Lisboa. Em que pese a busca de Viotti por considerar as ações concretas dos indivíduos e os acontecimentos dados pelas circunstâncias, sua análise, como declara, centrou-se em identificar as estruturas através da documentação, compreendendo a emancipação política dentro das "determinações gerais do processo histórico". Desta feita, esteve interessada em compreender o contexto em que se insere da emancipação dentro do quadro de crises do Antigo Regime e do sistema colonial diante das transformações do liberalismo na Europa. Em sua análise, o governo do período pós-independência ficou a cargo das forças sociais "conservadoras", interessadas em manter a estrutura tradicional de produção da grande propriedade baseada na escravidão e na exportação de gêneros tropicais. A realização da emancipação política pelas categorias dominantes, "cujo único objetivo era romper o sistema colonial no que ele significava de restrição à liberdade de comércio e à autonomia administrativa", imprimiria limites de prin- convocado em fevereiro daquele ano, tornar-se-ia um ponto de inflexão na questão da representação das partes da nação portuguesa, matéria que se demonstrava cada vez mais problemática nas cortes lisboetas ${ }^{8}$. Dai que a historiografia relativa ao periodo tenha registrado imagens calcando-se em certa memória dos acontecimentos ${ }^{9}$, que ajudou a consolidar e a construir, na qual o Revérbero seria separatista ${ }^{10}$. Da mesma forma, a partir de uma leitura dicotômica que contrapôs "conservadores" e "radicais", incutiu-se a imagem de que o jornal possuiria tendências manifestamente republicanas, sendo integrante de forças "radicais" ligadas às demandas populares ${ }^{11}$.

De outra parte, para reprodução destas interpretações, somaram-se explicações de certo viés historiográfico que tenderam a ver as ações concretas dos agentes sociais naquele momento histórico específico como reflexos imediatos de determinações macroestruturais de longa duração, ou como expressões precárias e artificiais da assimilação do liberalismo e dos principios constitucionais na Europa ${ }^{12}$, diante da suposta incongruência entre as idéias e as instituições liberais e a sociedade de caráter marcadamente escravista. Nesta versão, a história política do período estaria subsumida ao processo de desmantelamento do Antigo Regime europeu e do sistema colonial, ao passo que os limites intransponiveis da escravidão e da estrutura sócio-econômica agrária funcionariam como entrave decisivo para uma genuína assimilação dos princípios liberais e constitucionalistas. Assim, a defesa destas idéias em escritos como os do Revérbero, se faria de maneira entendida como limitada, já que, no Brasil, seu sentido revolucionário seria esvaziado pela apropriação dos indivíduos ilustrados e cultos, pertencentes às camadas intermediárias e altas da população ${ }^{13}$.

Não se trata, vale dizer, de reduzir a importância da longa contextualização histórica que caracterizou a crise do sistema das relações sociais e políticas enraizadas antes do século XVIII na Europa. De fato, ao se tratar das relações sociais vivenciadas em meio ao desmantelamento das formas tradicionais de legitimidade política, é necessário ter-se como horizonte de análise os antecedentes comuns, nomeadamente a larga conjuntura de crise do Antigo Regime e a presença do sistema escravista, que enquadraram e estabeleceram, de forma mais ou menos evidente, a ação dos agentes históricos, as possibilidades e limites dos seus projetos políticos ${ }^{14}$. 0 que certamente não descarta a necessidade de um olhar atento sobre os interesses práticos que motivaram as ações individuais e coletivas, que no caso do nosso estudo refere-se àqueles que gravitavam em torno dos projetos defendidos, de maneira mais ou menos explicitada, por Ledo e Cunha Barbosa nas páginas do Revérbero.

Foi Cecília Oliveira ${ }^{15}$ quem primeiro descortinou a atuação do jornal das interpretações centradas nas relações passionais entre os protagonistas e do enquadramento macroestrutural. A autora indicou uma complexa rede de interesses políticos e econômicos em disputa no momento, um conflito de interesses em torno da distribuição do poder político na Corte e da obtenção de lucros pelo comércio que envolveu donos de engenhos e lavouras mercantis do Recôncavo da Guanabara e de Campos dos Goitacazes, burocratas, comerciantes varejistas e negociantes atacadistas vinculados ao comércio de gêneros de abastecimento.

Estes estavam alijados das esferas decisivas de poder e passaram a rivalizar com o pequeno grupo que há muito ocupava os cargos mais altos da administração pública, formado por membros da nobreza e da 
cipio. Nesse sentido, ao discorrer sobre as contradições que observou entre a ideologia liberal, ostentada pelas classes dirigentes, e a "estrutura" da sociedade, que permaneceu colonial, apenas envolta por uma "fachada liberal", concluiu ter sido incompleta a emancipação definitiva, bem como o alargamento dos princípios constitucionais. COSTA, Emilia Viotti da. Introdução ao Estudo da Emancipação Política do Brasil. In: . Da Monarquia à República: momentos

decisivos. 8a ed. São Paulo: Fundação Editora Unesp, 2007. p.62.

13

Ibidem, p.61-62.

14

JANCSÓ, Istvan \& PIMENTA, João Paulo G. Peças de um mosaico (ou apontamentos para um estudo da emergência da identidade nacional brasileira). In: MOTA. Carlos Guilherme (org.). Viagem Incompleta; a experiência brasileira (1500-2000). São Paulo: SENAC, 2000.

\section{5}

OLIVEIRA, Cecilia Helena Lorenzini de Salles. A astúcia liberal. Bragança Paulista: Edusf e İcone, 1999.

\section{6}

Ibidem, p.238.

\section{7}

GOMES, Ângela de Castro. História, historiografia e cultura política no Brasil: algumas reflexões. In: SOIHET, Rachel; BICALHO, Maria Fernanda Baptista; GOUVEIA, Maria de Fátima (org). Culturas Políticas. Ensaios de história cultural, história política e ensino de história. Rio de Janeiro: Editora Mauad / FAPERJ, 2005.

\section{8}

Para o debate público da década de 1820 em Portugal e no Brasil respectivamente: VARGUES, Isabel Nobre. A aprendizagem da cidadania em Portugal (1820-1823). Coimbra: Minerva História, 1997 e NEVES, Lúcia Maria Bastos Pereira das. Corcundas e Constitucionais. A cultura política da Independência (1820-1822). Rio de Janeiro: Editora Revan/ FAPERJ, 2003. burguesia portuguesa emigrada e por grandes negociantes e proprietários pertencentes às poderosas famílias fluminenses. Em sua análise, a autora avaliou de que forma o novo contexto inaugurado em Portugal com a convocação das Cortes em 1820, acarretou numa circunstância em que a possibilidade de mudança político-institucional no governo seria vista pelos setores que se sentiam prejudicados na sua participação política e na disputa de mercados, como uma oportunidade de ampliação do acesso à cúpula do poder. Nas páginas do Revérbero, e também do Correio, estariam expressos tais planos de concomitantes reajustamentos da monarquia e do poder.

A autora reconheceu ainda a constituição de princípios políticos distintos no discurso do Revérbero. Como observou, ainda que defendessem fundamentos políticos que garantiam aos cidadãos o direito de representação, e o de escolher diretamente a quem caberia a elaboração das leis, seu projeto não era diminuir ou suprimir a hierarquia na participação política. Ao defenderem as eleições diretas, aproximando-se das regulamentações eleitorais estabelecidas pelas cortes lisboetas, estes liberais não aboliam as discriminações entre os cidadãos, mas as admitiam de outras maneiras. Os limites da liberdade de participação política evidenciavam-se nas clivagens existentes entre cidadãos e não-cidadãos, e principalmente entre eleitores e elegiveis ${ }^{16}$. Assim sendo, o acesso efetivo à esfera política pública seria atributo de um seleto grupo apto a participar da nova organização do poder político a ser estabelecida na Constituição. De fato, é de suma importância, para a análise das ações e projetos implementados a partir do jornal, ressaltar a relação entre as disputas e tramas políticas, os conflitos em torno da distribuição do poder e da busca pela obtenção de lucros. Todavia, entender os parâmetros da ação dos redatores do jornal, coerentes com o vocabulário que veiculavam, implica em aprofundar no exame do seu sistema de referências e práticas políticas e culturais, variáveis importantes da inteligibilidade e definição dos objetivos pretendiam alcançar. Como apontou Ângela de Castro Gomes, ainda que a cultura política seja constituída por elementos diversos e até mesmo conflitantes "pode guardar coerência e permitir a produção de interpretações da realidade, sendo fundamental para a construção de identidades"17.

Afinal, foi através da larga produção de impressos e da formação de uma ampla rede de debates no Brasil e em Portugal que se divulgaram as idéias e os conceitos fundamentais da cultura politica liberal e do constitucionalismo presentes nos debates do período. Pautando a nova linguagem do constitucionalismo liberal estavam as discussões sobre os princípios ligados ao regime de representação política, designadamente envolvendo visões do pacto social, da soberania, da divisão dos poderes e da legitimidade do novo governo a ser instituído. Da mesma forma, eram postas em evidência as matérias que abrangiam o novo estatuto social da cidadania, tais como a da definição dos direitos civis e políticos e dos deveres do cidadão. Por estar inserido nesse contexto e por incluir-se entre a literatura de circunstância que compartilhava dos fundamentos da cultura política do liberalismo constitucional que eclodiu, no Brasil e em Portugal, em $1820^{18}$, a análise do jornal, bem como dos propósitos e interesses de seus redatores, não pode ser desvinculada da compreensão das fronteiras e pertencimentos que caracterizavam sua identidade política. 
19

OLIVEIRA, Cecilia Helena Lorenzini de Salles. Na querela dos folhetos: 0 anonimato dos autores e a supressão de questões sociais. Revista de História, São Paulo, n.116, p.55-65, janeirojunho, 1984

20

Sobre conceito moderno de soberania, ver: François-Xavier Guerra em : GUERRA, FrançoisXavier. De la Política Antígua a la Política Moderna. La Revolución de la Soberania. In: GUERRA, François-Xavier; LEMPERIERE, Annick (org.) Los espacios públicos en Iberoamérica: Ambiguedades y problemas. Siglos XVIIIXIX. México: Fondo de Cultura Económica I Centro Francés de Estúdios Mexicanos y Centroamericanos, 1998.

\section{Problemas e perspectiva de análise}

0 jornal foi publicado no período entre 15 de setembro de 1821 e 8 outubro de 1822. Possuía em média 12 páginas, onde constavam matérias variadas, como atos governamentais e trechos de diversos autores e jornais estrangeiros que geralmente expressavam opiniões próximas. Apresentava-se também a sessão de "Correspondências", da qual faziam parte pedidos, sugestões e críticas pronunciadas, em sua maioria, através do anonimato ou de pseudônimos por homens que, muitas vezes, pertenciam à administração da Corte e da província ${ }^{19}$. Na parte intitulada "Reflexões" eram pronunciadas idéias e palavras dos próprios redatores que, no entanto, eram expressas em todo o jornal, em que sempre figuravam matérias de caráter editorial. Quase todos os jornais do periodo continham frases ou versos que juntamente com o título do jornal forneciam, mesmo ao leitor apressado, indícios da orientação e das intenções do periódico. No Revérbero havia na primeira página a inclusão de uma epígrafe, em que se exprimia de maneira concisa o posicionamento do jornal. Seu lema era: Redire sit nefas! Verso da Ode II do livro $5^{\circ}$ de Horácio ao Povo Romano, que significa: voltar atrás é um crime. A legenda referia-se a condenação contra o retorno do despotismo e da situação colonial, do então Reino do Brasil.

Como temos afirmado, os escritos e o discurso do Revérbero estiveram afinados com o ideário dos liberais vintistas de Portugal. Isto é, expressavam uma proposta de regeneração, de aperfeiçoamento da monarquia aos novos tempos liberais e constitucionais. De fato, a empreitada constitucionalista na América portuguesa desafiou e ao mesmo tempo redefiniu a regeneração política da monarquia e do império no Brasil. 0 ato de desafiar, entretanto, não culminou na aprovação integral da experiência revolucionária da França, mas exprimiu os anseios por mudanças que atendessem às novas demandas da conjuntura revolucionária sem ruptura total com as instituições e tradições, tais como a monarquia e a religião. Ao afirmarem uma nova fonte de poder e de autoridade, centrada na "Soberania do Povo"20, os redatores apelava à imagem de Rousseau, se afastando do antigo "contrato" de sujeição à vontade arbitrária do monarca e validando, pela lei, a primazia da "vontade geral" da nação. $\mathrm{Na}$ esteira da soberania residindo "essencialmente" na nação, tal como definiram as Bases da Constituição Política da Monarquia Portuguesa, aprovadas nas Cortes em março de 1821, alegariam que a esta caberia feitura da Constituição por meio de seus representantes legitimamente eleitos. Entretanto o engajamento na criação de uma ordem política que depositasse nos membros da sociedade a base do pacto social, ação típica de parte dos liberais constitucionalistas no Brasil e em Portugal do início do século XIX, não deve ser visto dentro da difundida tese que classifica este tipo de atuação como "revolucionária" ou a assinala necessariamente como "radicalismo".

Situando a primeira experiência constitucionalista de Portugal no contexto da Restauração, firmada no Congresso de Viena e identificada na Carta constitucional francesa de 1814, Antônio Manuel Hespanha argumentou que por baixo do "discurso da continuidade" fundava-se um projeto de "profundas reformas politico-institucionais e sociais", que, uma vez propostas, não retomariam as condições "pré-revolucionárias". Nesse sentido, o autor alerta para a distinção entre a opção dos vintistas pelo campo conservador do liberalismo, consubstanciada na 
HESPANHA, António Manuel. Guiando a mão invisivel. Direitos, Estado e Lei no liberalismo monárquico português. Coimbra: Almedina, 2004, p.125.

\section{2}

HESPANHA, António Manuel. Guiando a mão invisivel. Direitos, Estado e Lei no liberalismo monárquico português. Coimbra: Almedina, 2004, p. 125 .

23

Sobre as relações históricas entre liberalismo e constitucionalismo, ver: MATEUCCI, Nicola. Organización del poder y libertad: história do constitucionalismo moderno. Madrid: Trotta, 1998. p.259-284.

\section{4}

MOREL, Marco. As transformações dos espaços públicos: imprensa, atores políticos e sociabilidades na Cidade Imperial, 1820-1840. São Paulo: Hucitec, 2005. p.63.

\section{5}

Fazemos referência ao conceito cunhado por lara Lis para além de abranger o "foro intimo" e a "personalidade do indivíduo" acomoda-se "pelo artifício com que sua figura é externamente elaborada, ou seja, aquilo que de fora Ihe confere sentidos sociais, politicos, eficácias num jogo de representações e anseios políticos." SOUZA, lara Lis Carvalho. A Pátria Coroada: 0 Brasil como corpo político autônomo (1780 1831). São Paulo: Editora da UNESP, 1999. p.36. "ideologia da continuidade", e a adesão às novas concepções do contexto revolucionário ${ }^{21}$. Em outras palavras, ainda que se tratasse de uma postura conservadora, na medida em que visava, mais do que o desmantelamento das instituições, reforma e conservação da ordem social, não se tratava da continuidade das fórmulas absolutistas, mas de significativas transformações jurídico-institucionais, tais como a repartição dos poderes, a defesa de direitos individuais, de liberdades públicas e representatividade.

Assim, diferentemente das idéias constitucionais do final do século XVIII em Portugal, que visavam ao ordenamento jurídico do Estado e à administração do poder22, a Constituição, para estes constitucionalistas liberais do início do século XIX, tanto em Portugal como no Brasil, era entendida como um texto que deveria necessariamente postular ou propor a efetiva liberdade dos cidadãos. Porém, deve-se ter em mente que a geração que viveu as intensas transformações nas concepções e práticas políticas em fins do século XVIII e início do XIX, experimentou sob formas enviesadas e diversas a afirmação da dogmática constitucional (seus conceitos e concepções), e do liberalismo que o constitucionalismo daqueles anos trouxe inevitavelmente à discussão ${ }^{23}$. Como demonstraria a diferença de perspectivas no Brasil e em Portugal, que originou o rompimento da politica constitucionalista, as propostas políticas e projetos de Estado e de nação recorrentemente variavam de acordo com o momento, o espaço geográfico e o lugar social a partir do qual eram veiculadas. Deste modo, cabe considerar que mesmo os redatores se referenciando de modo geral na cultura política do vintismo, os objetivos que defendiam se referenciavam igualmente por sua própria realidade, e nem sempre convergiam com as propostas constitucionais largamente defendidas nas Cortes e posteriormente e estabelecidas na Constituição portuguesa de 1822.

Como afirmou Marco Morel ao analisar a questão das identidades políticas no Brasil entre 1820 e 1840, em um período de majoritária defesa do liberalismo "como apologia de tudo o que era constitucional", é necessário se ater às concepções e práticas de poder, que informavam significações diferenciadas sobre a Constituição e as liberdades dos cidadãos $^{24}$. Nesse sentido, vale recuar para os debates nos meses de julho e agosto de 1822, em meio às adesões em torno da persona de D. Pedro 25 e diante das precipitações que o novo quadro institucional da regência trazia, isto é, a convocação da Constituinte. Seria equivocado, vale dizer, considerar os últimos meses de 1822 como simples preliminares da oficialização da Independência nos moldes em que ocorreu, ou como prévia, em termos de constituição política e institucional, da consolidação do Estado monárquico no Brasil. De fato, as definições em torno da representação da soberania nacional, e as demais questões em termos de organização institucional da monarquia no Brasil, ainda permaneceriam inconclusas, pelo menos até 0 fechamento da Constituinte em 1823 e da outorga da carta constitucional de 1824, redigida pelo segundo Conselho nomeado por D. Pedro I. Por outro lado, as discussões e os encaminhamentos que se deram no jornal no tocante a questões deste tipo nos oferecem indícios válidos para o estudo de suas referências e práticas políticas.

Em suas "Reflexões", publicadas em 30 de julho de 1822, os redatores buscariam demarcar posições, elucidando a maneira como concebiam alguns pressupostos do sistema constitucional a ser implantado. 0 artigo em questão era um esclarecimento e uma resposta a um texto publicado 
26

Correio do Rio de Janeiro, n.77, 16 de julho de 1822.

27

Correio do Rio de Janeiro, n.77, 16 de julho de 1822.

28

Revérbero Constitucional Fluminense, n.10, 30 de julho de 1822.

\section{9}

Vide, por exemplo: Revérbero Constitucional Fluminense, n.03, 15 de outubro de 1821.

30

PIMENTA, João Paulo. Portugueses, americanos, brasileiros: identidades na crise do AntigoRegime luso-americano. Almanack Brasiliense, São Paulo, n.03, p.69-80, $1^{\circ}$ semestre de 2006.

31

Revérbero Constitucional Fluminense, n.11, 22 de janeiro de 1822 . no Correio do Rio de Janeiro dias antes, em 16 de julho, no qual o seu redator, João Soares Lisboa, acusava a pretensão à volta do despotismo pelos que planejavam a implantação do veto real às leis propostas pelo Legislativo, e o estabelecimento de uma "Câmara de Nobres", por critério de hereditariedade, juntamente com aquela eleita pelo voto, que a seu ver era a única em que figurava legitimamente a representação nacional 26. Segundo Soares Lisboa, à "Câmara de Nobres", formada por indivíduos "criados no luxo e na abundância", seria conveniente dar sustentação ao despotismo, pois "por interesse próprio" esta tenderia a seguir as insinuações do rei que, com "veto absoluto é déspota, e os déspotas raríssimas vezes deixam de ser tiranos"27. Diante da condução do debate público para tais questões, a posição do Revérbero seria criticar a excitação de tais desconfianças entre o "Povo" e o "Governo", até mesmo porque, diziam, tanto o príncipe quanto o ministério, desde a convocação da Constituinte em junho daquele ano, já teriam dado "as maiores provas de Liberalidade, e de Desvelo pela causa do nosso País". Na sua argumentação apontaria as razões desta desconfiança:

\footnotetext{
Um, aflige-se por demonstrar que o Rei não deve ter veto, inculcando desse modo, que teme que ele o queira ter; esquecendo-se que a Nação e o Rei, são os que devem fazer a Lei, porque ambos são igualmente interessados. Outro, chama desgraça as duas Câmaras, e já lhe parece ver uma numerosa classe de Fidalgos, que não temos, e fazendo hereditário o direito de assentar-se em uma delas, sem recordar-se ao menos, que a América do Norte, Republicana como é, tem um Senado, e uma Câmara de Representantes, sem que isto tenha eclipsado a sua fulgurosa Liberdade. 28
}

A menção elogiosa ao sistema constitucional do regime republicano da América do Norte era feita com tranqüilidade por um jornal que reiteradas vezes, e desde o início da sua publicação em fins de 1821, havia demonstrado sua preferência pela monarquia constitucional, em contraposição à democracia, entendida como sinônimo de anarquia e, sobretudo em 1821, associada à situação de guerra civil e desagregação territorial que assolava as jovens repúblicas da América espanhola 29. Como se sabe, a posição de enaltecimento da "regeneração política" da nação portuguesa que incluía o Brasil sofreria abalos e redefinições na passagem para o ano de 1822, com a chegada das deliberações que exigiam o retorno do príncipe e abolição dos Tribunais Superiores do Rio de Janeiro. No Revérbero, a mesma retórica antes usada para falar contra os males do Antigo Regime passou a ser evocada para amparar a autonomia do Reino do Brasil, isto é, o vocabulário antes usado para ressaltar os traços de união da nação passou a ser utilizado para matizar as peculiaridades do Brasil, bem como para defender seus direitos. Já no início de 1822, em uma publicação do dia 22 de janeiro, os escritos do jornal se voltariam para uma identificação cada vez maior com a situação política americana ${ }^{30}$ identificada ao constitucionalismo das independências da América Espanhola e dos Estados Unidos. A América passava, assim, a estar toda unida em uma comum "Zona Constitucional", contando com "mais de 25 milhões de homens livres", mas da qual o Brasil guardava ainda suas especificidades: "O Brasil adotando o Príncipe, adotou o partido mais seguro: vai gozar dos bens Liberdade sem as comoções da Democracia, e sem as violências da Arbitrariedade."31 
32

MATEUCCI, Nicola. Organización del poder y libertad: história del constitucionalismo moderno. Madrid: Trotta, 1998. p.253-258.
33

Revérbero Constitucional Fluminense, n.10, 30 de julho de 1822.

34

LOPES, José Reinaldo de Lima. Iluminismo e jusnaturalismo no ideário dos juristas da primeira metade do século XIX. In: JANCSÓ, István (org.) Brasil: formação do Estado e da nação. São Paulo / ljui: Fapesp / Hucitec / Unijui, 2003.
35

Ibidem. p.205
Apesar da adesão às Cortes ter sido definitivamente abalada em fins de 1821, como se percebe, o apoio à monarquia constitucional se intensificou, centrando-se na figura de D. Pedro. É claro que o fato de um dos redatores, Joaquim Gonçalves Ledo, ter passado a integrar, desde junho de 1822, o Conselho de Procuradores, muito influenciaria na declarada confiança que o jornal dizia depositar no rei e no governo naquele período. Por outro lado a defesa de um Estado forte, centrada na figura do monarca, associava-se a intenção de se afastar a tão almejada modernização do país das rupturas bruscas com a ordem social estabelecida. Tratava-se, assim, da difundida concepção, de certas vertentes liberalismo e do constitucionalismo do início do XIX ${ }^{32}$, de que era preciso garantir os direitos e liberdades dos cidadãos por meios estáveis. Dessa forma, para ilustrar o bom equilibrio entre os diversos poderes, mencionavam, no artigo de 30 de julho de 1822, o "célebre Benjamim Constante", para quem em "uma Monarquia Representativa o Rei deve possuir todo o poder, que é compatível com a Liberdade", pois a "segurança do Monarca é uma das garantias da Liberdade, e esta segurança só pode nascer da consciência e convicção de uma força suficiente". Da mesma maneira expressavam a sua concepção de soberania, que, a despeito do reconhecimento dos limites da autoridade real e da defesa das origens populares da soberania, não culminava, no jornal, com a justificação de um poder e liberdade irrestritos ao "Povo". A soberania popular que defendiam expressar-se-ia melhor através das instituições representativas do que por meio de usurpações diretas, e, portanto deveria ser limitada e circunscrita pelos mecanismos do sistema constitucional:

\footnotetext{
Se todo o Despotismo é ilegal, segue-se conseguintemente, que é mister não dar uma latitude indefinida a esta Soberania, onde quer que se ela ache, para que não degenere em arbitrariedade. Se concedemos a um homem um poder imenso, derivado da Divindade, ou se estabelecemos que a Soberania do Povo é ilimitada, criamos e lançamos ao acaso na Sociedade humana um grau de poder desmarcadamente grande em si mesmo e que por si mesmo é um mal, ou seja confiado a um, a alguns, ou a todos. A latitude do poder degenera sempre em Despotismo; por conseqüência é o grau de força, e não os depositários dela que nos devemos recear. 33
}

José Reinaldo de Lima Lopes ${ }^{34}$ analisou recentemente o ideário dos juristas no Brasil na primeira metade do século XIX, e reconheceu uma ambigüidade no seu discurso e prática legislativa procedente da tensão existente entre o novo ideário liberal constitucionalista, afirmado nas primeiras décadas, e a tradição "pré-liberal", que tinha antecedentes na Ilustração e no jusnaturalismo racionalista, trazidos pela formação jurídica da Universidade de Coimbra reformada. Abordou que o constitucionalismo no Brasil na primeira metade daquele século, com sua defesa comum do direito natural moderno e da feitura de códigos, deu origem a diferentes tipos de projetos constitucionais. Ao mesmo tempo em que se concebia um constitucionalismo fundado exclusivamente na soberania de bases populares, se admitia a idéia de uma sociedade dominada pela vontade do rei, nos moldes da cultura jurídica do período pombalino, que traduziria certo ideal no qual a Constituição seria entendida mais como "o código dos códigos do que o estatuto dos cidadãos" 35 . 
36

SABATO, Hilda (cood.). Ciudadania politica e formación de las naciones: perspectivas históricas de América Latina. México: Fondo de Cultura Económica, 1999. p.35.
Assim, entende-se que divergências de projetos na Corte naqueles anos estavam não só relacionadas aos interesses privados, mas também a adesões e a concepções identificadas com preceitos político-jurídicos do constitucionalismo e do liberalismo, os quais muitas vezes eram forjados em diferentes círculos de sociabilidades. A perseguição aos redatores do Revérbero e do Correio, iniciada com a devassa instaurada em 2 de novembro de 1822, a "Bonifácia" como ficou conhecida, tornaria evidente a intolerância do ministro José Bonifácio e de seus correligionários em relação à concepção política de um regime representativo que, a seu ver, rivalizava com a autoridade do imperador. Além dos confrontos ideológicos, as desavenças existentes expressavam, não obstante, a própria ambigüidade da modernidade política, a qual afetaria diretamente a constituição política e institucional da nova nação que se forjava. Como ensinou FrançoisXavier Guerra "as maneiras de conceber o homem, a sociedade, o poder político não são universais nem no espaço nem no tempo", o que faz com que a compreensão dos regimes políticos modernos e de suas respectivas sociedades seja "antes de tudo uma tarefa histórica" de "estudar um largo e complexo processo de invenção em que elementos intelectuais, culturais, sociais e econômicos estão imbricados intimamente com a política"36. É nessa integradora perspectiva de história política e do papel do sujeito histórico que buscamos nos inserir. 